\title{
Induction of labour using balloon catheter as an outpatient versus prostaglandin as an inpatient: a cost-effectiveness analysis.
}

\author{
Katharina Merollini ${ }^{1}$ and Michael Beckmann ${ }^{2}$ \\ ${ }^{1}$ University of the Sunshine Coast \\ ${ }^{2}$ Mater Health Services Brisbane
}

July 1,2020

\begin{abstract}
Objective: To assess the cost-effectiveness of induction of labour (IOL) with outpatient balloon catheter cervical priming versus inpatient prostaglandin (PG) vaginal gel or tape. Design: Economic evaluation alongside a multi-centre, randomized controlled trial. Setting: Eight Australian maternity hospitals. Population: A total of $n=448$ women with a live singleton pregnancy, cephalic presentation, at or beyond $37+0$ weeks gestation, undergoing IOL for low-risk indications between September 2015 and October 2018. Methods: An economic decision tree model was designed from a health services perspective. Sensitivity and subgroup analyses were performed to test the robustness of model outcomes. Main Outcome Measures: We estimated resource use from time of IOL to discharge of mother and infant, collected data on health outcomes (using EQ-5D-3L questionnaire) and reported cost per quality-adjusted life year (QALY) gained, incremental cost-effect ratio (ICER) and net monetary benefit (NMB). Results: Deterministic analysis showed lower mean costs (AUD $\$ 7,294$ versus AUD $\$ 7,585$ ) in the outpatient-balloon $(\mathrm{n}=205)$ compared to the inpatient-PG group $(\mathrm{n}=243)$, with better health outcomes (0.75 vs 0.74 QALYs gained) and overall higher NMB ( $\$ 30,054$ vs $\$ 29,338)$. In probabilistic analyses outpatient-balloon IOL was cost-effective in $55.3 \%$ of all simulations and $59.1 \%$ for women with favourable cervix (modified Bishop score $>3$ ) and $64.5 \%$ for nulliparous women. Conclusions: Outpatient-balloon IOL might be cost-saving compared to inpatient IOL with PG and is most likely to be cost-effective for nulliparous women. Funding: There was no external funding source for this study. Keywords: Decision analysis, labor induced, cost-effectiveness, prostaglandin, balloon ripening, randomised controlled trial
\end{abstract}

\section{Introduction}

Induction of labour (IOL) is a medical intervention to stimulate the onset of labour to facilitate vaginal birth of the baby. Despite the World Health Organisation, recommending IOL 'only when there is a clear medical indication for it and the expected benefits outweigh its potential harms', there has been an ongoing increasing trend in IOL worldwide (1). In Australia, less than half (43\%) of women now experience spontaneous labour, with most common medical indication for IOL reported as diabetes $(14 \%)$, prolonged pregnancy $(12 \%)$ and prelabour rupture of membranes (10\%) (2).

Although IOL is very common, there is no standard approach, and numerous methods and protocols of IOL are utilized. There is some high-quality data about clinical outcomes to inform best-practice (3-9), but scant data about women's healthcare experiences (10-15) and even less is known as to the healthcare costs. Given limited information on healthcare costs for IOL and scarce healthcare resources, it is imperative that we identify methods of IOL that are safe, effective, acceptable to women, and cost-effective.

Outpatient management is an appealing approach to undertaking IOL. It typically involves the woman attending hospital for a pre-IOL cardiotocography, administration of a cervical priming agent, going home, and then returning to hospital hours later for an amniotomy and oxytocin infusion (if labour has not ensued). Recently we published the largest randomized controlled trial (RCT) of outpatient IOL and demonstrated 
that outpatient balloon cervical ripening may be a safer method of IOL for nulliparous women, compared to using prostaglandin E2 (PG) as an inpatient (16). We have also shown that outpatient balloons are an acceptable method and more desirable than inpatient management with PG for many women (15).

This paper presents the cost-effectiveness analysis from our recently published trial of outpatient IOL (16). The aim was to determine if there are differences in quality of life and healthcare costs comparing outpatient cervical priming using a double-balloon catheter with the use of PG as an inpatient and to assess the overall probability of cost-effectiveness.

\section{Methods}

\section{RCT design}

A multi-center randomized controlled trial was undertaken across eight Australian maternity hospitals, between September 2015 and October 2018. The study compared the use of outpatient balloon catheter cervical priming IOL with inpatient PG (Dinoprostone) vaginal gel or tape. The methods are described in detail elsewhere (16). In summary, eligible women had a live singleton pregnancy, cephalic presentation, at or beyond $37+0$ weeks gestation, and were undergoing IOL for low-risk indications. Women presented to hospital in the early evening. Those randomized to the inpatient-PG group were admitted to hospital, administered PG as $2 \mathrm{mg}$ Dinoprostone vaginal gel (Prostin) or $10 \mathrm{mg}$ Dinoprostone controlled-release vaginal tape (Cervidil), and then remained as an inpatient until birth. Women randomized to the outpatient-balloon group had a double-balloon catheter (Cervical Ripening Balloon plus stylet; Cook Medical, Bloomington, US) placed during a digital vaginal examination. Following 30 minutes of observation, the woman was given written information about the reasons to return earlier and how to call the hospital, and discharged home for approximately 12 hours. For women in both groups, early clinical review occurred if there was vaginal bleeding, fluid loss, painful contractions, expulsion of the balloon, or the woman needed pain relief. Otherwise, women were reviewed in birth suite the following morning, approximately 12 hours after commencement of her IOL. At this review, an amniotomy was attempted, and a Syntocinon infusion commenced as soon as possible. Women completed a written questionnaire postpartum (prior to hospital discharge), measuring their healthcare experience and this included an assessment of health-related quality of life. The primary outcome measure was a composite measure of neonatal outcomes. Healthcare cost was a secondary outcome measure.

\section{Economic Evaluation}

\section{A. Model structure}

A decision model was developed in the form of a decision tree to compare the short-term outcomes for women who received PG as an inpatient with those who received a balloon catheter as an outpatient. A health services perspective was chosen for the evaluation, from hospital admission until discharge home of mother and baby. Women moved through mutually exclusive model pathways, according to transition probabilities associated with each model arm. The model distinguished the two comparators (balloon group, PG group) for nulliparous vs parous women and their probabilities of mode of birth (unassisted vaginal, instrumental or caesarean section (CS)) and baby requiring nursery admission vs postnatal ward care. The model structure is illustrated in the Supplementary material (Figures S1 \& S2).

\section{B. Model input parameters}

Resource use: Detailed finance data was only available for the lead study site, and these data have been used for all participants. Costs have been estimated inclusive of nursing / midwifery, medical and allied health staff costs, equipment and consumables, pharmacy, pathology, radiology, hotel services and business overheads. These have been calculated as a cost per hour of admission to antenatal ward, birth suite, theatre, postnatal ward and neonatal nursery. Cervical priming cost (PGE2 gel, PGE2 tape, cervical ripening balloon) was available at the patient level, whereas the hourly costs for each inpatient clinical unit have been calculated by dividing total cost by total clinical hours. The precise durations of care in each clinical unit was recorded for all 448 trial participants who were induced. 
Health outcomes: Health status was measured using the generic EQ-5D-3L questionnaire and comprised (a) five domains: mobility, self-care, usual activities, pain/discomfort and anxiety/depression with 3 response levels each (no problems, some problems and extreme problems); and (b) a self-reported summary measure of health, using a visual analogue score (EQVAS), ranging from 0 (worst imaginable health state) to 100 (perfect health) (17). These health state assessments were available for 359 women who completed their assessment. The health utility index ranged from 0 (worst possible health) to 1 (best possible health) and values represented the utility scores used in the model according to Australian population norms (18).

Transition probabilities: Transition probabilities between model pathways were derived by calculations from observed events in the actual trial data (see Supplementary material, Figure S2). As no deaths were observed we did not include any risk of mortality associated with either method of IOL.

\section{Data analyses}

Results were analysed according to the method of IOL received. Mean costs (and standard deviation) are expressed in Australian dollars (AUD) at 2019. The cost-effectiveness was estimated for the two competing methods of IOL received, and the expected values of direct costs and health utilities were calculated for each model pathway (see Supplementary material, Figure S2). Total costs were calculated as a sum of all applicable cost components per model pathway, including mean priming cost, cost of CS and mean length of stay (in hours) in each clinical unit (antenatal ward, birth suite, postnatal ward, special nursery) multiplied by the corresponding mean hourly cost of stay. Deterministic model outcomes are presented as cost per quality-adjusted life year (QALY) and as incremental cost-effectiveness ratio (ICER), where the difference in cost ([?]C) is divided by the difference in effectiveness ([?]E). We also calculated the Net Monetary Benefit $(\mathrm{NMB})$ including the willingness-to-pay $(\lambda)$ per additional outcome where NMB $=\left(\lambda^{*}[?] \mathrm{E}\right)-[?] \mathrm{C}(19)$. The strategy with the highest NMB is the recommended strategy. Results were not discounted due to the short time frame of the evaluation. TreeAge Pro 2020, R1.1 software was used for all cost-effectiveness, sensitivity and subgroup analyses (20).

Probabilistic sensitivity analysis was performed as Monte Carlo simulations by adding model distributions for input parameters at the same time and running the model 10,000 times. Beta distributions were fitted around utility parameters and gamma distributions around cost and length of stay parameters using the mean values and standard deviations for each pathway. The results are presented graphically on the costeffectiveness acceptability curve and on the cost-effectiveness plane. We assumed a willingness-to-pay (WTP) of the standard $\$ 50,000$ per QALY gained (21). In one-way sensitivity analyses only a single value from a range of possible values is tested at a time whilst all other parameters remain the same. We performed oneway sensitivity analyses for the cost of CS, hourly cost of stay in antenatal ward, birth suite, postnatal ward, intensive care nursery and special care nursery. Subgroup analyses were performed for parity (nulliparous vs parous) and cervical favourability at start of IOL (modified Bishops score (MBS) [?]3 vs >3) and the impact on model outcomes was recorded.

\section{Results}

Health outcomes, resource use and costs are summarised in Table 1 by method of IOL. Most women in the balloon and PG group were nulliparous ( $72.7 \%$ and $67.1 \%$, respectively) and birthed vaginally $(67.8 \%$ and $73.6 \%$ respectively), with more women in the PG group starting IOL with a more favourable cervix (MBS $>3$ ) compared to the balloon group (56.2\% vs $47.7 \%)$. Health utility index scores showed lower health scores for nulliparous ( 0.726 balloon vs 0.694 PG group) than for parous women ( 0.80 balloon vs 0.834 PG groups) and higher health scores for vaginal birth (0.804 unassisted, 0.705 instrumental) compared to CS (0.643). Health utility scores were marginally higher for women starting IOL with a less favourable (MBS[?]3 compared to more favourable cervix (0.744 vs 0.738). Balloon catheters cost $\$ 49$ and the mean cost of PG cervical ripening was $\$ 105$. Hourly cost of care in the antenatal ward was $\$ 51, \$ 259$ in the birth suite, $\$ 48$ in the postnatal ward and $\$ 81-\$ 125$ in the neonatal nurseries.

Deterministic model analyses showed costs in the balloon group $(\mathrm{n}=205)$ and PG group $(\mathrm{n}=243)$, were $\$ 9,765$ versus $\$ 10,272$ per QALY gained, retrospectively (see Table 2 ). The balloon group absolutely dominated the 
PG group with lower mean costs $(\$ 7,294$ vs $\$ 7,585)$ and higher mean effectiveness (0.75 vs 0.74 QALYs), resulting in a negative ICER which indicates cost savings of $\$ 34,193$ per quality-adjusted life year gained if this method of induction was chosen. The net monetary benefit (NMNB) of outpatient-balloon IOL was $\$ 30,054$ compared to $\$ 29,338$ in the PG group.

In probabilistic sensitivity analyses (PSA) using Monte Carlo simulation, the balloon group had a higher probability of being cost-effective at each WTP threshold tested (see Figure 1). At a WTP of $\$ 50,000$ the likelihood of outpatient-balloon IOL being cost-effective is $55.25 \%$ compared to inpatient-PG IOL (44.75\%). Figure 2 shows the scatter plot on the incremental cost-effectiveness plane for both methods. The eclipse represents the $95 \%$ confidence interval of all simulated pairs of incremental cost-effectiveness from the 10,000 simulations. A total of $34.2 \%$ of all simulations fell in the south-east quadrant representing possible results in which outpatient-balloon IOL was less costly and more effective than inpatient-PG IOL. A further $17.8 \%$ of simulations fell in the north-east quadrant below the $\$ 50,000 \mathrm{WTP}$ threshold, indicating higher costs and higher benefits of outpatient-balloon IOL that we would be willing-to-pay for each additional QALY (below $\$ 50,000)$. Another $3.3 \%$ of simulations in the south-west quadrant indicate lower costs and lower benefits of outpatient-balloon IOL below the WTP threshold. Overall, the area to the right of the WTP threshold line is the number of simulations $(34.2 \%+17.8 \%+3.3 \%=55.3 \%)$ in which outpatient-balloon IOL represents the better value for money, and the area to the left represents simulations in which inpatient-PG IOL is cost-effective (44.7\%).

Extracts of results from 1-way sensitivity analyses are illustrated in the Supplementary material, Table S1. When the mean operating costs per CS with baseline value of $\$ 3,447$ were varied from $\$ 1,000-\$ 15,000$, outpatient-balloon IOL had a higher NMB for each tested value and dominated inpatient-PG IOL up to a cost of $\$ 8,442$. Furthermore, varying the mean hourly cost in antenatal ward of $\$ 51$ from $\$ 0-\$ 150$ also showed consistently higher NMB for balloon induction which had lower costs and higher effectiveness (absolute dominance) for values between $\$ 28$ to $\$ 150$. One-way sensitivity analysis of mean hourly costs in birth suite with baseline value of $\$ 259$ was tested for values between $\$ 100-\$ 500$ and resulted in higher NMB for each value with lower costs and higher effectiveness in the balloon group for values up to $\$ 450$. The tested ranges of mean costs of stay in postnatal ward (baseline value $\$ 48$, range $\$ 0$ - $\$ 100$ ), ICN (baseline value $\$ 125$, range $\$ 50$ - $\$ 200$ ) and SCN (baseline value $\$ 81$, range $\$ 0$ - \$300) resulted in absolute dominance (lower cost, higher effectiveness) of outpatient-balloon IOL with higher NMB $(\$ 27,399-\$ 32,505)$ compared to inpatient-PG IOL (NMB from $\$ 26,757$ - $\$ 31,721)$.

Subgroup analyses by parity also indicated a higher likelihood of outpatient-balloon IOL being cost-effective for nulliparous women $(64.5 \%)$ and inpatient-PG IOL being cost-effective for parous women (66.9\%). The NMB for inpatient-PG IOL in parous women was the highest out of all types of analyses (see Table 2) with $\$ 36,969$ compared to balloon induction in parous women with $\$ 34,210$ and very low mean costs for parous women in both groups with $\$ 4,903$ for PG and $\$ 5,659$ in the balloon group. Subgroup analyses by cervix favourability showed higher mean costs for both methods of IOL for women with a more favourable cervix (MBS >3) compared to a less favourable cervix (MBS [?]3), and higher probability (59.1\%) of outpatientballoon IOL being cost-effective for women with a more favourable cervix (NMB $\$ 30,599$ vs $\$ 27,904$ ). Women with a less favourable cervix had lower mean costs by $\$ 759$ and higher utility scores by 0.026 in the inpatientPG IOL with $56.3 \%$ of simulations indicating cost-effectiveness.

\section{Discussion}

\section{Main findings}

Outpatient-balloon IOL is cost-saving with lower costs and better health outcomes than inpatient-PG IOL. The robustness of these findings was tested through sensitivity analyses varying the costs of CS, and the mean hourly costs in antenatal ward, birth suite, postnatal ward, and neonatal nurseries. In all tested scenarios, outpatient-balloon IOL was favoured, with consistently higher NMB and an ICER below the WTP threshold. Although outpatient-balloon IOL had a higher mean NMB and lower cost/QALY gained these results are not conclusive that outpatient-balloon IOL is the preferred alternative for all women. Indeed, the 
probabilistic sensitivity analyses showed outpatient-balloon IOL was cost-effective $55.3 \%$ of the time. The subgroup analyses by parity, however, more strongly indicated cost-effectiveness of outpatient-balloon IOL for nulliparous women (NMB $\$ 28,420$ vs $\$ 25,675$ ) and inpatient-PG IOL for parous women (NMB $\$ 36,969$ vs $\$ 34,210)$. Subgroup analysis by cervix favourability was surrounded by higher levels of uncertainty.

The difference in cost outcomes between the two methods of IOL was largely due to the amount of time spent in the antenatal ward. Outpatient-balloon IOL was associated with a saving of almost 13 hours in antenatal ward care and, consequently, the mean costs were more than six times higher in the inpatient-PG group (\$781 vs $\$ 129$ ). Furthermore, cervical priming costs in the balloon group were less than half that of the PG group ( $\$ 49$ vs $\$ 105$ ). The mean length of stays in birth suite and in the postnatal ward were slightly longer in the balloon group $(\sim 1.5 \mathrm{hrs})$ which may reflect the higher proportion of nulliparous women in this group ( $72.7 \%$ vs $67.1 \%$ ), who typically experience a longer labour and longer postnatal stay than parous women. Whilst acknowledging the inherent difficulties in costing each hour of care in each clinical unit, these findings highlight the importance of considering location and not just the duration of care when designing cost-effective models of care. Our findings from a health services perspective suggest that using outpatient-balloon IOL is expected to be cost-saving, especially for nulliparous women. In practical terms cervical priming costs will be reduced and less time spent in antenatal wards is expected to reduce costs as well as free up both hospital beds and staff time. The actual impact within health services might differ between facilities and should be further explored in future studies.

\section{Strengths and limitations}

This research has generated detailed data on utility weights and costs relating to IOL that can be used in other economic evaluations. It adds to the scarce literature in this context. Conducting a cost-utility analysis (CUA) with generic health outcome measure (QALY) rather than other types of cost-effectiveness analyses (CEA) with outcomes measured in clinical terms (e.g. reduction in stillbirths), enables comparison to other cost-effectiveness outcomes across different fields, and aids decision-makers in selecting healthcare interventions with best value for money. In addition, we used real-life data from a large multi-centre RCT including actual costs and clinical events observed. The results of this trial have been reported in three phases, including clinical outcomes (16), women's preferences (15) and now cost-effectiveness outcomes. Our findings from different angles strengthen the confidence in our conclusions with the economic benefit, safety and preference of nulliparous women for outpatient-balloon IOL.

Although this was the largest RCT of outpatient IOL undertaken, more research with larger patient cohorts and in different settings is warranted to confirm our conclusions and explore generalisability of results. The costing approach also had some limitations due to the nature of administrative records as hourly costs per length of stay in each clinical unit were calculated based on patient cohort averages (bottom-down approach) rather than a sum of each individual cost component per patient (bottom-up approach), which is regarded as the gold standard in costing. We are nonetheless confident that our costing methodology did not significantly influence overall costs since all relevant components were detailed, including midwifery, nursing, medical and allied health staff costs, pathology, radiology, equipment, consumables, hotel services and business overheads. Furthermore, the time horizon in this evaluation only included immediate adverse events until discharge from hospital for both mother and baby. It is possible that some women may have experienced long-term physical or psychological impact associated with their birth experience, but this was beyond the scope of this study. Finally, all model-based analyses have inherent limitations and might not capture all real-world events.

\section{Interpretation}

Several economic evaluations of IOL have been undertaken, including comparing IOL at 39 weeks (22-24) or 41 weeks (25) to expectant management. An Australian study of outpatient (Foley) catheter with inpatient IOL (26) found non-significantly higher mean costs ( $\$ 6,524$ OCF and $\$ 5,876 \mathrm{IPG}$ ). Although not directly comparable to our study as they did not include a generic health outcome measure, they did similarly report significantly fewer antenatal ward hours in outpatient-balloon compared to inpatient-PG group. We observed a slightly longer and more expensive stay in birth suite for women in outpatient-balloon group, as was also 
reported in two Dutch CEA alongside RCTs $(27,28)$. From a health economic perspective, it is therefore tempting to consider outpatient-PG IOL, with a potential reduction in cervical priming costs and time spent in antenatal ward, especially for nulliparous women whose duration of induced labour can be prolonged. However, our findings were of more adverse perinatal outcomes amongst nulliparous women receiving PG (16). A 2014 systematic review, meta-analysis and CEA on best method of IOL (29) found most interventions compared had similar utility but differed on cost outcomes. Titrated misoprostol solution and sublingual misoprostol had the highest probability of being cost-effective. But given their increased rates of uterine hyperstimulation, compared to mechanical methods, misoprostol may also not be appropriate for outpatient cervical priming. Future outpatient IOL studies should consider the role of alternative mechanical methods, or different durations of insertion in order to determine safe, cost-effective approaches that are acceptable to women.

The decision-making around the choice of IOL method is complex and is likely influenced by best-practice guidelines, clinician/health service preferences, but also women's' beliefs, past experiences and willingness to undergo a certain intervention. Although a clinician's principal focus may be to provide high-quality care, they share responsibility for making the best decisions for a health system with finite resources, by choosing cost-effective care options. In this study, outpatient-balloon IOL resulted in both cost-saving and improved health outcomes with reduced uncertainty for nulliparous women representing excellent value for money. These findings should be considered for future decision-making, along with evidence on safety and women's preferences.

\section{Conclusion}

The economic evaluation alongside RCT demonstrated that outpatient-balloon IOL was more likely to be cost-effective compared to inpatient-PG IOL and could be cost-saving. For nulliparous women (outpatientballoon IOL) and for parous women (inpatient-PG IOL), the uncertainty surrounding cost-effectiveness is reduced. These findings were reported from a health services perspective and will aid decision-makers to allocate scarce resources efficiently.

\section{Disclosure of interests}

None declared.

\section{Contribution to authorship}

MB designed and supervised the RCT and KM advised on the collection of variables relevant for the costeffectiveness evaluation. Both MB and KM conducted statistical analyses and KM designed, evaluated and interpreted the economic decision model. All authors were involved in drafting and editing of the manuscript and approved of the final version.

\section{Details of ethics approval}

The trial was granted ethics approval from the Mater Health Services Human Research Ethics Committee on 6 March 2014 (HREC/14/MHS/20).

\section{Funding}

No financial support was provided.

\section{Acknowledgements}

We would like to thank the staff at finance department of the Mater Hospitals in Brisbane, Queensland, who helped with extracting hospital costs, as well as midwives and staff who collected the trial data. We are grateful to all the women who participated in the trial and made this research possible.

\section{Supporting Information}

Additional Supporting Information may be found in the online version of this article: 
Figure S1. Simplified structure of decision model

Figure S2. Transition probabilities used in decision tree

Table S1. 1-way Sensitivity Analyses Results

\section{References}

1. World Health Organization (WHO). WHO recommendations: induction of labour at or beyond term. Geneva: WHO; Licence: CC BY-NC-SA 3.0 IGO; 2018.

2. Australian Institute of Health and Welfare (AIHW). Australia's mothers and babies 2018-in brief. Canberra:: AIHW; 2020.

3. Vogel JP, Osoti AO, Kelly AJ, Livio S, Norman JE, Alfirevic Z. Pharmacological and mechanical interventions for labour induction in outpatient settings. Cochrane Database Syst Rev. 2017;9:CD007701.

4. Tulek F, Gemici A, Soylemez F. Double balloon catheters: A promising tool for induction of labor in multiparous women with unfavorable cervices. J Turk Ger Gynecol Assoc. 2019;20(4):231-5.

5. Kehl S, Weiss C, Wamsler M, Beyer J, Dammer U, Heimrich J, et al. Double-balloon catheter and sequential vaginal prostaglandin E2 versus vaginal prostaglandin E2 alone for induction of labor after previous cesarean section. Arch Gynecol Obstet. 2016;293(4):757-65.

6. Vaknin Z, Kurzweil Y, Sherman D. Foley catheter balloon vs locally applied prostaglandins for cervical ripening and labor induction: a systematic review and metaanalysis. Am J Obstet Gynecol. 2010;203(5):41829.

7. Eser A, Ozkaya E, Abide CY, Eser T, Eser GY, Abike F, et al. Transcervical Foley balloon catheter and vaginal prostaglandin E2 insert combination vs. vaginal prostaglandin E2 insert only for induction of labor at term: a randomized clinical trial. Arch Gynecol Obstet. 2019;299(2):451-7.

8. Henry A, Madan A, Reid R, Tracy SK, Austin K, Welsh A, et al. Outpatient Foley catheter versus inpatient prostaglandin E2 gel for induction of labour: a randomised trial. BMC Pregnancy Childbirth. $2013 ; 13: 25$.

9. Queensland Clinical Guidelines: Translating evidence into best clinical practice. Maternity and Neonatal Clinical Guideline: induction of labour. Brisbane: Queensland Health March 2017.

10. Dupont C, Blanc-Petitjean P, Cortet M, Gaucher L, Salome M, Carbonne B, et al. Dissatisfaction of women with induction of labour according to parity: Results of a population-based cohort study. Midwifery. 2020;84:102663.

11. Lou S, Hvidman L, Uldbjerg N, Neumann L, Jensen TF, Haben JG, et al. Women's experiences of postterm induction of labor: A systematic review of qualitative studies. Birth. 2019;46(3):400-10.

12. Coates R, Cupples G, Scamell A, McCourt C. Women's experiences of induction of labour: Qualitative systematic review and thematic synthesis. Midwifery. 2019;69:17-28.

13. Lim SE, Tan TL, Ng GYH, Tagore S, Kyaw EEP, Yeo GSH. Patient satisfaction with the cervical ripening balloon as a method for induction of labour: a randomised controlled trial. Singapore Med J. 2018;59(8):419-24.

14. Ten Eikelder ML, van de Meent MM, Mast K, Rengerink KO, Jozwiak M, de Graaf IM, et al. Women's Experiences with and Preference for Induction of Labor with Oral Misoprostol or Foley Catheter at Term. Am J Perinatol. 2017;34(2):138-46.

15. Beckmann M, Acreman M, Schmidt E, Merollini KMD, Miller Y. Women's experience of induction of labor using PGE2 as an inpatient versus balloon catheter as an outpatient. Eur J Obstet Gynecol Reprod Biol. 2020;249:1-6. 
16. Beckmann M, Gibbons K, Flenady V, Kumar S. Induction of labour using prostaglandin E2 as an inpatient versus balloon catheter as an outpatient: a multicentre randomised controlled trial. BJOG. 2020;127(5):571-9.

17. Rabin R, de Charro F. EQ-5D: a measure of health status from the EuroQol Group. Ann Med. 2001;33(5):337-43.

18. Viney R, Norman R, King MT, Cronin P, Street DJ, Knox S, et al. Time trade-off derived EQ-5D weights for Australia. Value Health. 2011;14(6):928-36.

19. Weinstein MC, Stason WB. Foundations of cost-effectiveness analysis for health and medical practices. N Engl J Med. 1977;296(13):716-21.

20. TreeAge Software. 2020, R1.1. Williamstown, MA: Software available at http://www.treeage.com.

21. Lowe A, Dyson S. New Therapies for Advanced Cancers: Can Our Society Afford Them? Is it Ethical to Deny Patients Access to Them? Actuaries Institute 2013 Actuaries Summit; Sydney, Australia: Institute of Actuaries of Australia; 2013.

22. Callander EJ, Creedy DK, Gamble J, Fox H, Toohill J, Sneddon A, et al. Reducing caesarean delivery: An economic evaluation of routine induction of labour at 39 weeks in low-risk nulliparous women. Paediatr Perinat Epidemiol. 2020;34(1):3-11.

23. Hersh AR, Skeith AE, Sargent JA, Caughey AB. Induction of labor at 39 weeks of gestation versus expectant management for low-risk nulliparous women: a cost-effectiveness analysis. Am J Obstet Gynecol. 2019;220(6):590 e1- e10.

24. Walker KF, Dritsaki M, Bugg G, Macpherson M, McCormick C, Grace N, et al. Labour induction near term for women aged 35 or over: an economic evaluation. BJOG. 2017;124(6):929-34.

25. Kaimal AJ, Little SE, Odibo AO, Stamilio DM, Grobman WA, Long EF, et al. Cost-effectiveness of elective induction of labor at 41 weeks in nulliparous women. Am J Obstet Gynecol. 2011;204(2):137 e1-9.

26. Austin K, Chambers GM, de Abreu Lourenco R, Madan A, Susic D, Henry A. Cost-effectiveness of term induction of labour using inpatient prostaglandin gel versus outpatient Foley catheter. Aust N Z J Obstet Gynaecol. 2015;55(5):440-5.

27. Ten Eikelder M, van Baaren GJ, Oude Rengerink K, Jozwiak M, de Leeuw JW, Kleiverda G, et al. Comparing induction of labour with oral misoprostol or Foley catheter at term: cost-effectiveness analysis of a randomised controlled multi-centre non-inferiority trial. BJOG. 2018;125(3):375-83.

28. van Baaren GJ, Jozwiak M, Opmeer BC, Oude Rengerink K, Benthem M, Dijksterhuis MG, et al. Cost-effectiveness of induction of labour at term with a Foley catheter compared to vaginal prostaglandin E(2) gel (PROBAAT trial). BJOG. 2013;120(8):987-95.

29. Alfirevic Z, Keeney E, Dowswell T, Welton NJ, Medley N, Dias S, et al. Which method is best for the induction of labour? A systematic review, network meta-analysis and cost-effectiveness analysis. Health Technol Assess. 2016;20(65):1-584.

\section{Figure Legend:}

- Figure 1: Monte Carlo Cost-Effectiveness Acceptability Curve

- Figure 2: Incremental Cost-effectiveness results of balloon versus PG group shown on the Costeffectiveness plane

Table 1: Overview of clinical, health and resource use data used in decision tree (2019 \$AUD) based on $\mathrm{n}=448$ trial participants 


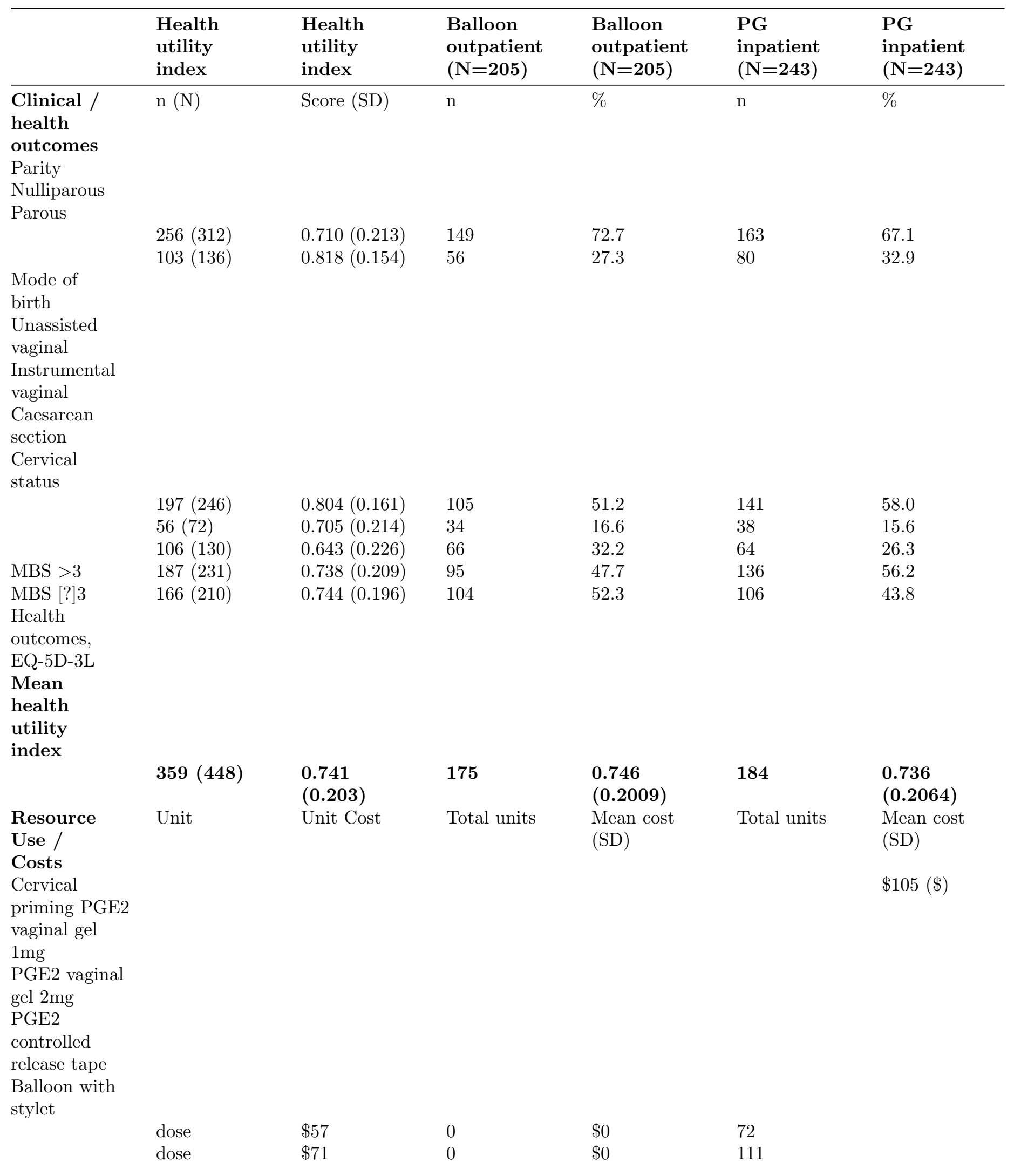




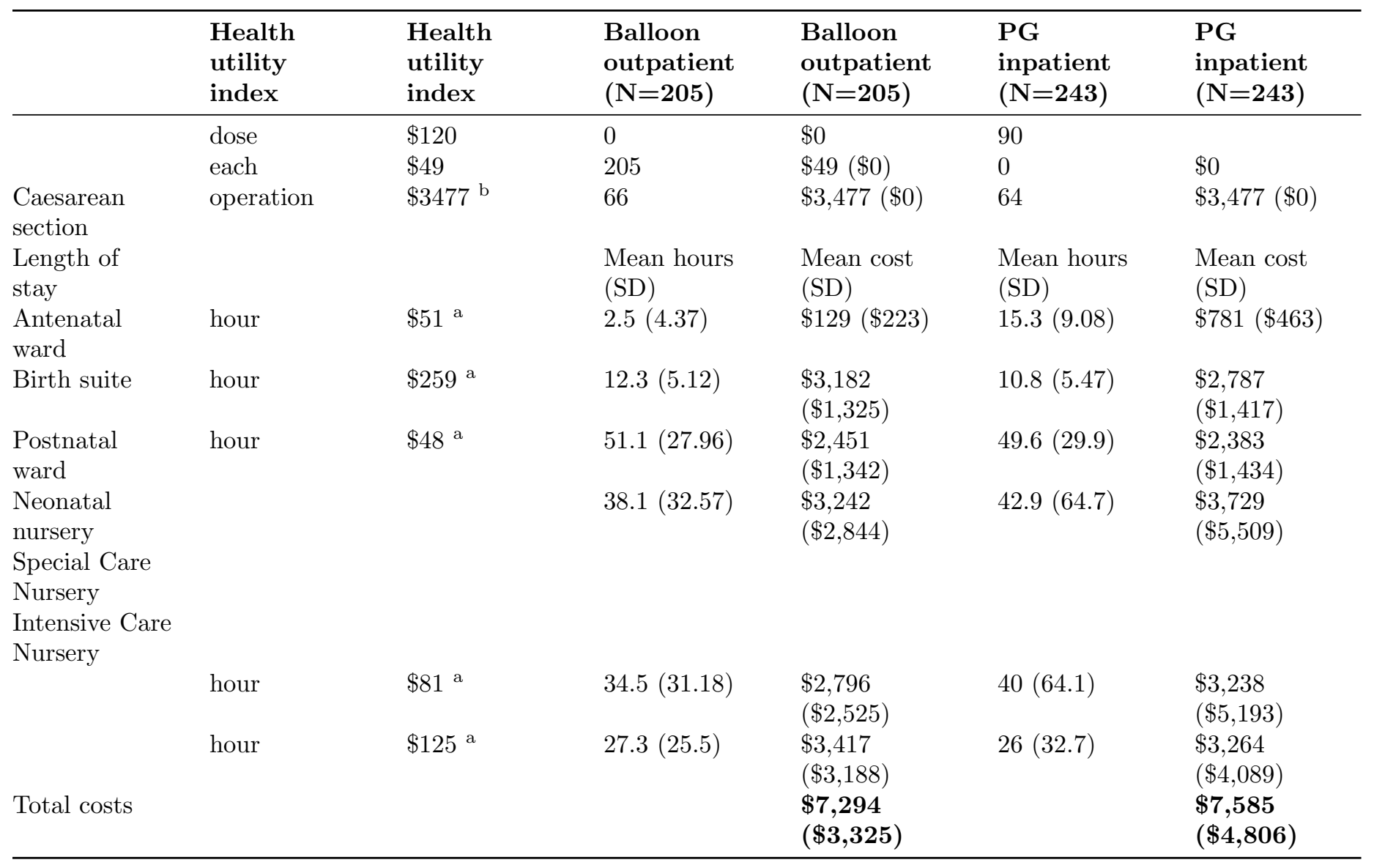

a per hour of admission, inclusive of midwifery, nursing, medical and allied health staff costs, pathology, radiology, equipment, consumables, hotel services and business overheads

${ }^{\mathrm{b}}$ mean cost per procedure in operating theatre and then recovery, inclusive of medical nursing and anaesthetic staff costs, equipment, consumables and business overheads

Table 2: Summary of Cost-effectiveness Results by type of Analysis

\begin{tabular}{lllllllll}
\hline $\begin{array}{l}\text { Type of } \\
\text { Analysis }\end{array}$ & Strategy & $\begin{array}{l}\text { Cost (in } \\
\text { \$AUD) }\end{array}$ & $\begin{array}{l}\text { Incremental } \\
\text { Cost }\end{array}$ & $\begin{array}{l}\text { Effect in } \\
\text { QALY }\end{array}$ & $\begin{array}{l}\text { Incremental } \\
\text { Effect }\end{array}$ & ICER & NMB & $\begin{array}{l}\text { Cost/QALY } \\
\text { gained }\end{array}$ \\
\hline DeterministicDeterministicDeterministicDeterministicDeterministicDeterministicDeterministicDeterministicDeterministicDe \\
/
\end{tabular}




\begin{tabular}{|c|c|c|c|c|c|c|c|c|}
\hline $\begin{array}{l}\text { Type of } \\
\text { Analysis }\end{array}$ & Strategy & $\begin{array}{l}\text { Cost (in } \\
\text { \$AUD) }\end{array}$ & $\begin{array}{l}\text { Incremental } \\
\text { Cost }\end{array}$ & $\begin{array}{l}\text { Effect in } \\
\text { QALY }\end{array}$ & $\begin{array}{l}\text { Incremental } \\
\text { Effect }\end{array}$ & ICER & NMB & $\begin{array}{l}\text { Cost/QALY } \\
\text { gained }\end{array}$ \\
\hline Probabilistic & Probabilistic & Probabilistic & Probabilistic & Probabilistic & Probabilistic & Probabilistic & Probabilistic & Probabilistic \\
\hline $\begin{array}{l}\text { Sensi- } \\
\text { tivity }\end{array}$ & $\begin{array}{l}\text { Sensi- } \\
\text { tivity }\end{array}$ & $\begin{array}{l}\text { Sensi- } \\
\text { tivity }\end{array}$ & $\begin{array}{l}\text { Sensi- } \\
\text { tivity }\end{array}$ & $\begin{array}{l}\text { Sensi- } \\
\text { tivity }\end{array}$ & $\begin{array}{l}\text { Sensi- } \\
\text { tivity }\end{array}$ & $\begin{array}{l}\text { Sensi- } \\
\text { tivity }\end{array}$ & $\begin{array}{l}\text { Sensi- } \\
\text { tivity }\end{array}$ & $\begin{array}{l}\text { Sensi- } \\
\text { tivity }\end{array}$ \\
\hline \multirow[t]{3}{*}{$\begin{array}{l}\text { Analy- } \\
\text { sis } \\
(10,000 \\
\text { iterations })\end{array}$} & $\begin{array}{l}\text { Analy- } \\
\text { sis } \\
(10,000 \\
\text { iterations })\end{array}$ & $\begin{array}{l}\text { Analy- } \\
\text { sis } \\
(10,000 \\
\text { iterations })\end{array}$ & $\begin{array}{l}\text { Analy- } \\
\text { sis } \\
(10,000 \\
\text { iterations) }\end{array}$ & $\begin{array}{l}\text { Analy- } \\
\text { sis } \\
(10,000 \\
\text { iterations })\end{array}$ & $\begin{array}{l}\text { Analy- } \\
\text { sis } \\
(10,000 \\
\text { iterations })\end{array}$ & $\begin{array}{l}\text { Analy- } \\
\text { sis } \\
(10,000 \\
\text { iterations })\end{array}$ & $\begin{array}{l}\text { Analy- } \\
\text { sis } \\
(10,000 \\
\text { iterations })\end{array}$ & $\begin{array}{l}\text { Analy- } \\
\text { sis } \\
(10,000 \\
\text { iterations })\end{array}$ \\
\hline & $\begin{array}{l}\text { Balloon } \\
\text { group }\end{array}$ & $\$ 7,293$ & & 0.7464 & & & $\begin{array}{l}\$ \\
30,029\end{array}$ & $\$ 9,770$ \\
\hline & $\begin{array}{l}\text { PGE } \\
\text { group }\end{array}$ & $\$ 7,588$ & $\$ 295$ & 0.7395 & -0.0069 & $\begin{array}{l}-\$ \\
42,486\end{array}$ & $\begin{array}{l}\$ \\
29,387\end{array}$ & $\begin{array}{l}\$ \\
10,261\end{array}$ \\
\hline $\begin{array}{l}\text { Subgroup } \\
\text { analy- } \\
\text { sis: }\end{array}$ & $\begin{array}{l}\text { Subgroup } \\
\text { analy- } \\
\text { sis: }\end{array}$ & $\begin{array}{l}\text { Subgroup } \\
\text { analy- } \\
\text { sis: }\end{array}$ & $\begin{array}{l}\text { Subgroup } \\
\text { analy- } \\
\text { sis: }\end{array}$ & $\begin{array}{l}\text { Subgroup } \\
\text { analy- } \\
\text { sis: }\end{array}$ & $\begin{array}{l}\text { Subgroup } \\
\text { analy- } \\
\text { sis: }\end{array}$ & $\begin{array}{l}\text { Subgroup } \\
\text { analy- } \\
\text { sis: }\end{array}$ & $\begin{array}{l}\text { Subgroup } \\
\text { analy- } \\
\text { sis: }\end{array}$ & $\begin{array}{l}\text { Subgroup } \\
\text { analy- } \\
\text { sis: }\end{array}$ \\
\hline Parity & Parity & Parity & Parity & Parity & Parity & Parity & Parity & Parity \\
\hline \multirow[t]{2}{*}{ Nulliparous } & $\begin{array}{l}\text { Balloon } \\
\text { group }\end{array}$ & $\$ 7,928$ & & 0.7270 & & & $\begin{array}{l}\$ \\
28,420\end{array}$ & $\begin{array}{l}\$ \\
10,906\end{array}$ \\
\hline & $\begin{array}{l}\text { PGE } \\
\text { group }\end{array}$ & $\$ 8,914$ & $\$ 986$ & 0.6918 & -0.0352 & $\begin{array}{l}-\$ \\
28,026\end{array}$ & $\begin{array}{l}\$ \\
25,675\end{array}$ & $\begin{array}{l}\$ \\
12,886\end{array}$ \\
\hline \multirow[t]{2}{*}{ Parous } & $\begin{array}{l}\text { Balloon } \\
\text { group }\end{array}$ & $\$ 5,659$ & $\$ 756$ & 0.7974 & -0.0401 & $\begin{array}{l}-\$ \\
18,857\end{array}$ & $\begin{array}{l}\$ \\
34,210\end{array}$ & $\$ 7,097$ \\
\hline & $\begin{array}{l}\text { PGE } \\
\text { group }\end{array}$ & $\$ 4,903$ & & 0.8375 & & & $\begin{array}{l}\$ \\
36,969\end{array}$ & $\$ 5,855$ \\
\hline $\begin{array}{l}\text { Subgroup } \\
\text { analy- } \\
\text { sis: }\end{array}$ & $\begin{array}{l}\text { Subgroup } \\
\text { analy- } \\
\text { sis: }\end{array}$ & $\begin{array}{l}\text { Subgroup } \\
\text { analy- } \\
\text { sis: }\end{array}$ & $\begin{array}{l}\text { Subgroup } \\
\text { analy- } \\
\text { sis: }\end{array}$ & $\begin{array}{l}\text { Subgroup } \\
\text { analy- } \\
\text { sis: }\end{array}$ & $\begin{array}{l}\text { Subgroup } \\
\text { analy- } \\
\text { sis: }\end{array}$ & $\begin{array}{l}\text { Subgroup } \\
\text { analy- } \\
\text { sis: }\end{array}$ & $\begin{array}{l}\text { Subgroup } \\
\text { analy- } \\
\text { sis: }\end{array}$ & $\begin{array}{l}\text { Subgroup } \\
\text { analy- } \\
\text { sis: }\end{array}$ \\
\hline \multirow{3}{*}{$\begin{array}{l}\text { Cervi- } \\
\text { cal } \\
\text { status } \\
\text { MBS } \\
>3\end{array}$} & $\begin{array}{l}\text { Cervi- } \\
\text { cal } \\
\text { status }\end{array}$ & $\begin{array}{l}\text { Cervi- } \\
\text { cal } \\
\text { status }\end{array}$ & $\begin{array}{l}\text { Cervi- } \\
\text { cal } \\
\text { status }\end{array}$ & $\begin{array}{l}\text { Cervi- } \\
\text { cal } \\
\text { status }\end{array}$ & $\begin{array}{l}\text { Cervi- } \\
\text { cal } \\
\text { status }\end{array}$ & $\begin{array}{l}\text { Cervi- } \\
\text { cal } \\
\text { status }\end{array}$ & $\begin{array}{l}\text { Cervi- } \\
\text { cal } \\
\text { status }\end{array}$ & $\begin{array}{l}\text { Cervi- } \\
\text { cal } \\
\text { status }\end{array}$ \\
\hline & $\begin{array}{l}\text { Balloon } \\
\text { group }\end{array}$ & $\$ 7,353$ & & 0.7590 & & & $\begin{array}{l}\$ \\
30,599\end{array}$ & $\$ 9,687$ \\
\hline & $\begin{array}{l}\text { PGE } \\
\text { group }\end{array}$ & $\$ 8,424$ & $\$ 1,071$ & 0.7266 & -0.0325 & $\begin{array}{l}-\$ \\
32,977\end{array}$ & $\begin{array}{l}\$ \\
27,904\end{array}$ & $\begin{array}{l}\$ \\
11,594\end{array}$ \\
\hline \multirow[t]{2}{*}{$\begin{array}{l}\text { MBS } \\
{[?] 3}\end{array}$} & $\begin{array}{l}\text { Balloon } \\
\text { group }\end{array}$ & $\$ 7,189$ & $\$ 759$ & 0.7333 & -0.0260 & $\begin{array}{l}-\$ \\
29,221\end{array}$ & $\begin{array}{l}\$ \\
29,477\end{array}$ & $\$ 9,803$ \\
\hline & $\begin{array}{l}\text { PGE } \\
\text { group }\end{array}$ & $\$ 6,430$ & & 0.7593 & & & $\begin{array}{l}\$ \\
31,533\end{array}$ & $\$ 8,469$ \\
\hline
\end{tabular}




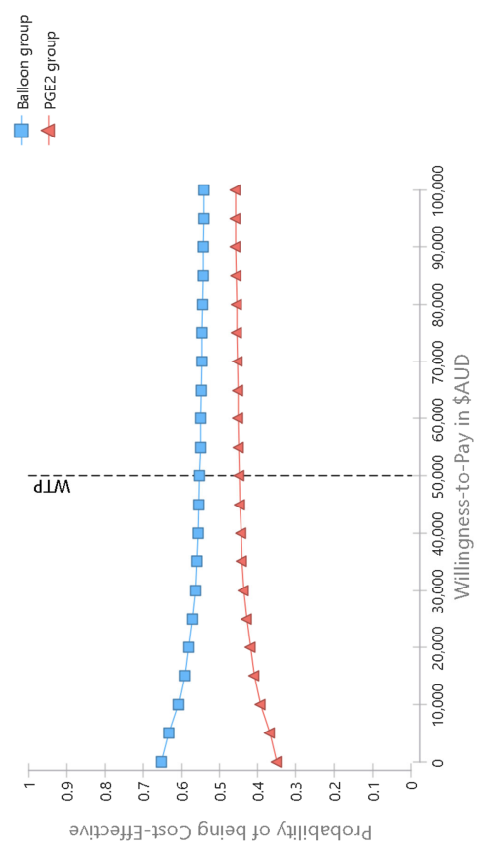




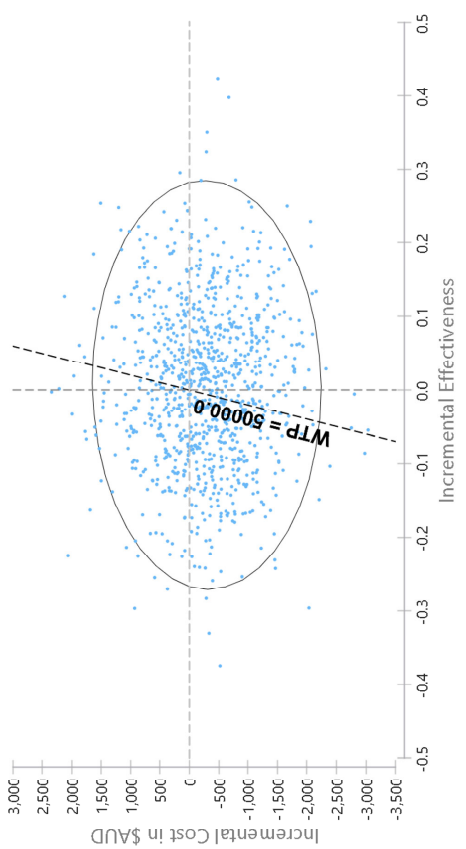

